\title{
Prevalence of obesity among Thai schoolchildren: a survey in Khon Kaen, Northeast Thailand
}

Phouvang Sengmeuang ${ }^{\mathrm{a}}$, Upa Kukongviriyapan ${ }^{\mathrm{a}}$, Orapin Pasurivong ${ }^{\mathrm{a}}$, Chulee Jones ${ }^{\mathrm{b}}$, Wilaiwan Khrisanapant ${ }^{\mathrm{a}}$ ${ }^{a}$ Department of Physiology, Faculty of Medicine, ${ }^{b}$ Department of Physical Therapy, Faculty of Associated Medical Sciences, Khon Kaen University, Khon Kaen 40002, Thailand.

\begin{abstract}
Background: There is a worldwide increase in obese children and adolescents. No systematized biometric data are available to confirm this trend in Thailand.

Objective: Estimate the prevalence of obesity among 12- to 18-years-old attending the secondary school in the municipality of Khon Kaen, Northeast Thailand.

Materials and methods: We used stratified, two-stage, cluster sampling to select 7,096 healthy boys and girls from 12,021 students of grades 7 to 12 at three government schools. Height and weight were measured to calculate body mass index (BMI) (weight (kg)/height $\left.(\mathrm{m})^{2}\right)$. Sex-specific, BMI-for-age growth charts were created from the data on the 2,593 boys and 4,503 girls (between 12 and 18 years of age) using simple random sampling. Sex-specific BMI-for-age growth charts and the weight-for-height $(\mathrm{W} / \mathrm{H})$ were used to estimate the prevalence of obesity and overweight.

Results: The respective national prevalence of obese and overweight children was $4.9 \%$ and $9.5 \%$ in the BMI-forage, the rates between boys and girls being comparable. There were no significant differences in the prevalence of either obesity or overweight with increasing age. In the Thai standard $\mathrm{W} / \mathrm{H}, 13.7 \%$ of the children were obese and 5.3\% were overweight. Obesity was more prevalent $n$ boys (18.9\%) than girls (10.8\%) and decreased with age. The prevalence of overweight did not change with age regardless of gender.

Conclusion: Obesity among children in Khon Kaen was similar to, or less prevalent than that reported for other areas of Thailand. The prevalence of obesity needs to be judged by the same (or similar) criteria before any comparison among various studies is done.
\end{abstract}

Keywords: Children, obesity, prevalence, Northeast Thailand

Obesity and overweight are identified as abnormal or excessive fat accumulation leading to serious health problems. Severe obesity in adulthood is more likely if obesity begins in childhood [1]. In 2005, the World Health Organization (WHO) reported that at least 20 million children under five years of age were obese around the world [2].

Body composition in children differs between boys and girls, and changes with age. The Centers

Correspondence to: Associate Professor Wilaiwan Khrisanapant, Department of Physiology, Faculty of Medicine, Khon Kaen University, Khon Kaen 40002, Thailand. E-mail: wilkhr@ kku.ac.th for Disease Control and Prevention (US-CDC) recommended that the classifications for overweight and obesity for children and adolescents should be age- and sex-specific [3].

The incidence of overweight and obesity varies among countries and age groups, but overall obesity trends to be higher in boys than in girls and decreases with age [4-12].

In Thailand, the prevalence of childhood obesity is reportedly between 9\% and 31\% [13-21]. However, systematized biometric data, as a whole or by region, are not available to confirm the increasing tread of obese children and adolescents in Thailand. 
In this study, we investigated the prevalence of overweight and obesity, creating sex-specific BMI for-age growth charts for children and adolescents in Khon Kaen municipality in Northeast Thailand. In the survey, we used the Thai Standard W/H for children between one day and 19 years of age.

\section{Materials and methods}

The study was approved by the Ethics Committee of Khon Kaen University. Data collection was done between June and August, 2007. Our sample included $59 \%(7,096 / 12,021)$ of the secondary school students, both boys and girls between 12 and 18 years of age, in the municipality of Khon Kaen. Sampling was done in two clusters at each of the three schools, Kanlayanawat School, Khon Kaen Wittayayon School, and Kaenakorn Wittayalai School. Students were issued a random number according to the class size.

Age was reckoned from the documented date of birth. We rounded age to a whole number. For example, 12-year-olds comprised all those between 11.5 and 12.4 years of age. This method of rounding was used for all ages.

\section{Anthropometric assessment}

Height, weight, hip and waist circumference were measured for each participant, according to the WHO guidelines [22]. Participants wore light clothing and no shoes. Weight was determined using a digital scale (TCS-150-B), to the nearest tenth. Height was measured standing with feet together and arms relaxed at the sides.

The BMI was calculated as weight $(\mathrm{W}, \mathrm{kg})$ divided by height $\left(\mathrm{H}, \mathrm{m}^{2}\right)$ and sex-specific, BMI-forage growth charts were created. A BMI $\geq$ the $95^{\text {th }}$ percentile indicated obesity, between the $85^{\text {th }}$ and $<$ the $95^{\text {th }}$ overweight, $\geq$ the $5^{\text {th }}$ and $<$ the $85^{\text {th }}$ normal, and $<$ the $5^{\text {th }}$ underweight. Since the $\mathrm{W} / \mathrm{H}$ criteria is commonly used in Thailand, we defined obesity and overweight using the Standard W/H criteria, that is a $\mathrm{W} / \mathrm{H}>^{+} 2.0 \mathrm{SD}$ (standard deviation) and $>^{+} 1.5 \mathrm{SD}$ to ${ }^{+}$2SD [11], respectively. The Institute of Nutrition, Mahidol University, which created the 'INMU-Thai Growth' program, allowed us to assess their data for the prevalence of obesity, overweight, normal weight, and underweight.

The outcome of our study is a population estimate of the prevalence of overweight vs. obese in boys and girls between 12 and 18 years of age.

\section{Statistical analysis}

Descriptive analyses were conducted to estimate the overall prevalence of overweight, obesity, normal and underweight. All statistical analyses were performed using STATA (version 10.0).

\section{Results \\ BMI-for-age}

The sex-specific, BMI-for-age growth charts for boys and girls based on the data of 7,096 children (36\% boys, 64\% girls) are presented in Fig. 1. By age, $10.8 \%, 16.1 \%, 18.1 \%, 14.7 \%, 16.0 \%, 16.7 \%$, and $6.4 \%$ of the population were $12,13,14,15,16,17$ and 18 years of age, respectively. Of the 2,593 boys, the highest and lowest percentage of the population was $21.4 \%$ at 14 years of age and $5.4 \%$ at 18 years, respectively.

Out of the 4,503 girls, the highest and lowest percentage of the population was $17.8 \%$ at 17 years of age and $7 \%$ at 18 years. There were no significant changes in the BMI with age, either among the boys or the girls at each percentile. For boys, the BMI-forage at the 95 percentile was $29.1 \mathrm{~kg} / \mathrm{m}^{2}$ at 12 years and $29.3 \mathrm{~kg} / \mathrm{m}^{2}$ at 18 years, whereas for girls it was $26.9 \mathrm{~kg} / \mathrm{m}^{2}$ at both 12 years and 18 years.

The average BMI for boys was slightly greater than for girls at the 75, 85, 90 and 95 percentiles. At the 95 percentile, for instance, the BMI for boys ranged between 28.1 and $29.5 \mathrm{~kg} / \mathrm{m}^{2}$ whereas for girls it was between 26.2 and $27.1 \mathrm{~kg} / \mathrm{m}^{2}$. Despite some differences, the BMI-for-age in boys and girls at the 5, 10, 25 and 50 percentiles were comparable.

The prevalence of obesity and overweight for children in 2007 is shown in Table 1 (Data for normal weight and underweight are not shown). Overall, 4.9\% of children between 12 and 18 were obese from a minimum of $4.6 \%$ at 16 to a maximum of $5.3 \%$ at 15 .

For boys, between 12 and 18, the prevalence of obesity was $4.8 \%$ (range, $4.3 \%$ at 18 to $5.3 \%$ at 15 years of age). Similarly, for girls between 12 and 18, the prevalence of obesity was $4.8 \%$ (range, from $4.5 \%$ at 16 to $5.3 \%$ at 15 years of age). In addition, the overall prevalence of overweight was $9.5 \%$, which was almost double that of obesity; namely, $9.4 \%$ in boys vs. $9.9 \%$ in girls.

\section{W/H criteria}

The prevalence of obesity and overweight for boys and girls using the $\mathrm{W} / \mathrm{H}$ differed from that using the BMI-for-age criteria (Table 1). Obesity was 2.58 
times more prevalent than that of overweight (13.7\% vs. 5.3\%). The percentage of obese boys was greater than girls (18.9\% vs. 10.8\%). Additionally, the prevalence of obesity appeared to decrease with age but not that of overweight in either boys or girls.

(A)

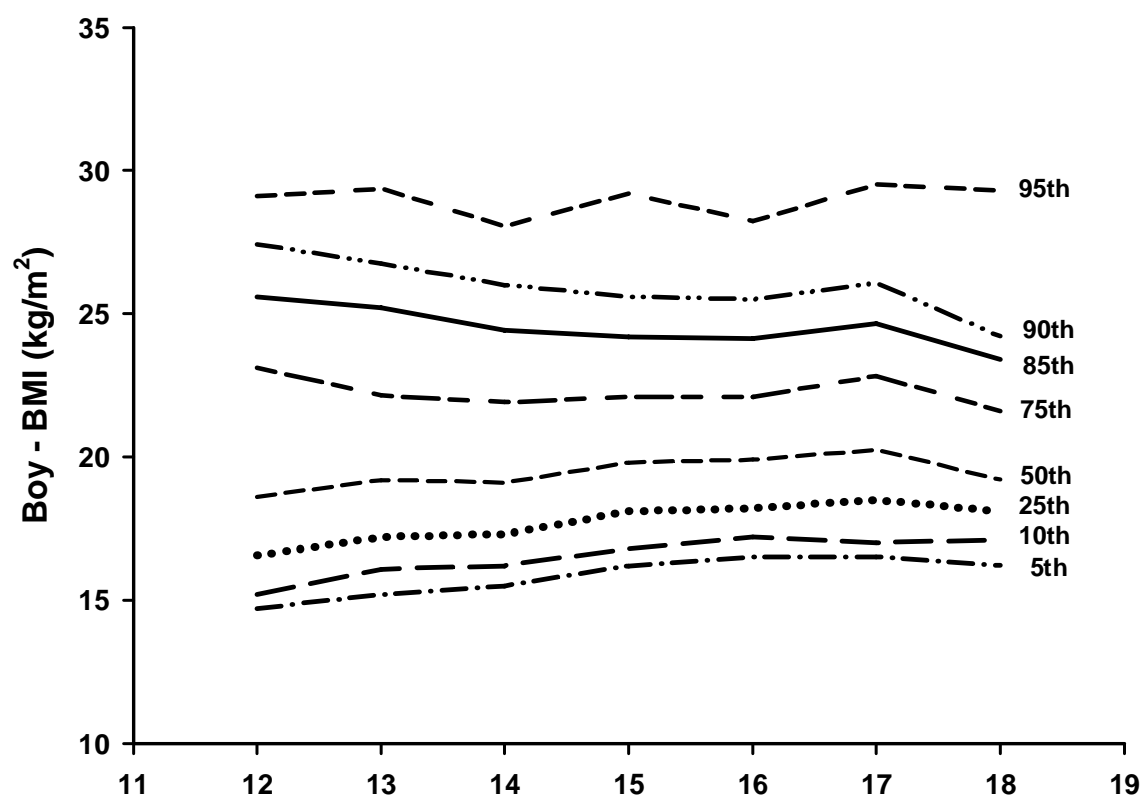

(B)

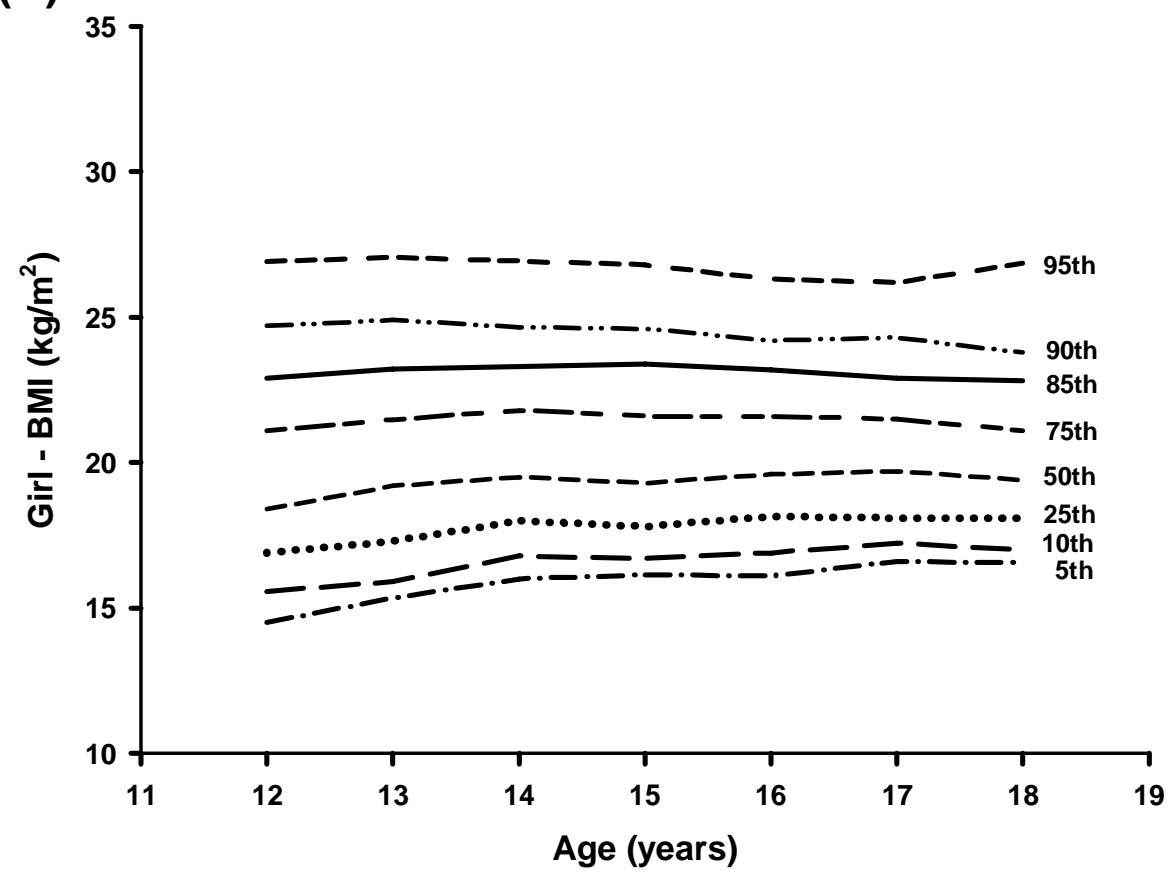

Fig. 1 Body mass index-for-age percentiles in boys (A) and girls (B): age 12 to 18 years. 
Table 1. Comparison of prevalence of obesity and overweight among 7,096 children (2,593 boys, 4,503 girls) in Khon Kaen, Thailand, as determined by the BMI-for-age percentiles and the weight for height.

\begin{tabular}{|c|c|c|c|c|c|c|c|c|}
\hline & Obese & & & & Overweight & & & \\
\hline & $\begin{array}{l}\text { BMI } \\
\geq 9^{\text {th }} \\
\text { percentile }\end{array}$ & & $\begin{array}{c}\text { W/H } \\
(>+2 S D)\end{array}$ & & $\begin{array}{c}\text { BMI } \\
\geq 85^{\text {th }} \text { to }<95^{\text {th }} \\
\text { percentile }\end{array}$ & & \begin{tabular}{l}
\multicolumn{1}{c}{$\mathrm{W} / \mathrm{H}$} \\
$(>+1.5 \mathrm{SD}-$ \\
$+2 \mathrm{SD})$
\end{tabular} & \\
\hline & Number & $\%$ & Number & $\%$ & Number & $\%$ & Number & $\%$ \\
\hline $\begin{array}{l}\text { Boys and girls, } \\
12-18 \text { years }\end{array}$ & 345 & 4.9 & 956 & 13.7 & 672 & 9.5 & 372 & 5.3 \\
\hline 12 & 41 & 4.8 & 133 & 16.4 & 86 & 10.1 & 39 & 4.8 \\
\hline 13 & 56 & 4.9 & 169 & 14.3 & 111 & 9.7 & 56 & 4.8 \\
\hline 14 & 62 & 4.8 & 177 & 13.9 & 122 & 9.5 & 68 & 5.4 \\
\hline 15 & 55 & 5.3 & 141 & 13.9 & 98 & 9.4 & 54 & 5.4 \\
\hline 16 & 52 & 4.6 & 134 & 12.0 & 99 & 8.7 & 64 & 5.8 \\
\hline 17 & 57 & 4.8 & 157 & 13.6 & 113 & 9.6 & 65 & 5.7 \\
\hline 18 & 22 & 4.8 & 45 & 10.2 & 43 & 9.5 & 26 & 5.9 \\
\hline Boys, $12-18$ years & 125 & 4.8 & 474 & 18.9 & 244 & 9.4 & 147 & 5.8 \\
\hline 12 & 16 & 4.8 & 77 & 23.0 & 35 & 10.4 & 21 & 6.3 \\
\hline 13 & 20 & 4.5 & 83 & 18.5 & 43 & 9.6 & 25 & 5.6 \\
\hline 14 & 29 & 5.2 & 97 & 17.7 & 53 & 9.6 & 26 & 4.7 \\
\hline 15 & 19 & 5.3 & 61 & 17.6 & 33 & 9.2 & 18 & 5.2 \\
\hline 16 & 18 & 4.8 & 63 & 17.6 & 32 & 8.5 & 22 & 6.2 \\
\hline 17 & 17 & 4.5 & 75 & 21.0 & 36 & 9.4 & 27 & 8.1 \\
\hline 18 & 6 & 4.3 & 18 & 13.9 & 12 & 8.6 & 8 & 6.2 \\
\hline Girls, $12-18$ years & 220 & 4.9 & 482 & 10.8 & 428 & 9.9 & 221 & 5.0 \\
\hline 12 & 25 & 4.9 & 56 & 11.7 & 51 & 9.9 & 18 & 3.8 \\
\hline 13 & 36 & 5.2 & 86 & 11.7 & 68 & 9.8 & 31 & 4.3 \\
\hline 14 & 33 & 4.5 & 80 & 11.1 & 69 & 9.4 & 42 & 5.9 \\
\hline 15 & 36 & 5.3 & 80 & 12.1 & 65 & 9.5 & 36 & 5.5 \\
\hline 16 & 34 & 4.5 & 71 & 9.4 & 67 & 8.8 & 42 & 5.6 \\
\hline 17 & 40 & 5.0 & 82 & 10.4 & 77 & 9.6 & 38 & 4.9 \\
\hline 18 & 16 & 5.1 & 27 & 8.6 & 31 & 9.8 & 18 & 5.8 \\
\hline
\end{tabular}

$\mathrm{BMI}=$ body mass index, $\mathrm{W} / \mathrm{H}=$ weight for height. 


\section{Discussion}

The present study provides sex-specific, BMI for-age, growth charts for Thai children/adolescents (between 12 and 18 years of age) in the municipality of Khon Kaen, Northeastern Thailand. There was no evidence to indicate that the BMI-for-age in either boys or girls increased with age. This does not agree with the 2000 US-CDC report for children in the United States for the same age group. In that study, the BMI for-age continued increasing from 12 (boys $24.2 \mathrm{~kg} / \mathrm{m}^{2}$, girls $25.2 \mathrm{~kg} / \mathrm{m}^{2}$ ) through to 18 years of age (boys $28.9 \mathrm{~kg} / \mathrm{m}^{2}$, girls $30.3 \mathrm{~kg} / \mathrm{m}^{2}$ ) and the prevalence of obesity among girls was greater than for boys [3]. The difference may be due to different diet and lifestyle as the American population is ethnically diverse.

In our study, the prevalence of overweight in boys or girls was approximately double that of obesity. The prevalence of obesity was comparable to that of German children [6], but approximately12\% less than in American children [4, 5], approximately 5\% less than in Portuguese children [7] and Indian children [9], while it was approximately $2 \%$ greater than in Indian children in another study [10] and approximately 3\% greater than in Iranian children [8]. Table 2 summarizes previous reports of incidence of overweight and obesity among countries and age groups.

A broad range in the prevalence of obesity using the $\mathrm{W} / \mathrm{H}$ has been reported among Thai children from different regions of Thailand. However, none of these other studies generated sex-specific BMI-for-age. By using the $\mathrm{W} / \mathrm{H}$, the prevalence of obesity agreed with the studies done in students between grades 7 and 12 in Phutthamonthon District, Nakhon Pathom Province [18] and in school children between 6 and 12 years of age from Hat Yai province [16]. However, it was less than the $26 \%$ of primary school students from Nakhon Pathom Province [21], or the respective 31\% and 30\% of Grade 6 children from Bangkok and Saraburi Province [14].
There have only been two studies done in the Northeast region, Sakon Nakorn [14] and Khon Kaen [15]. The prevalence of obesity in our study was approximately $5 \%$ less than that observed among the Grade 6 children from Sakon Nakorn. The only study performed among primary school children (between seven and nine years of age) in the municipality of Khon Kaen reported a 3\% lower rate of obesity than our study. Similarly though, they found obesity more prevalent among boys than girls (W/H: $13.5 \%$ vs. $8.0 \%$, or BMI-for-age: $15.6 \%$ vs. $10.1 \%$ ).

There has been only one study in Pattani province, South Thailand. It revealed a respective $10.7 \%$ and $12.7 \%$ lower prevalence of obesity for non-Muslim and Muslim children [13] than in our study, possibly because of differences in lifestyle and diet between South and Northeast children.

In conclusion, the prevalence of obesity among secondary school children in Khon Kaen Municipality, Northeast Thailand was less than that reported in most overseas studies using BMI-for-age. It might be more appropriate to use the $\mathrm{W} / \mathrm{H}$ when comparing the prevalence of obesity and overweight between Thai and overseas children. It is also suggested that a sexspecific, BMI for-age growth chart for Thai children be constructed.

\section{Acknowledgements}

The first author (P.S) received financial support for her MSc in Medical Physiology from World Bank and for her PhD in Medical Physiology from the Khon Kaen University Scholarship for Human Resource Development of Neighboring Countries and the Thailand International Development Cooperation Agency (TICA). This study received Research Grants from the Faculty of Medicine, Khon Kaen University. The authors thank Mr. B.R. Hamman and J. LoewenHamman for their English correction of the manuscript.

The authors have no conflict of interest to report.

Table 2. Incidence of overweight and obesity among countries and age groups.

\begin{tabular}{lcccc}
\hline Country & Time frame & Age group & \% Overweight & \% Obesity \\
\hline USA [4] & $1999-2002$ & $12-19$ & 14.8 & 16.1 \\
USA [5] & $2003-2006$ & $13-19$ & - & 17.4 \\
Germany [6] & 2006 & $3-17$ & 15 & 6.3 \\
Portugal [7] & 2007 & 13 & 16.5 & 10.2 \\
East Iran [8] & 2009 & $7-18$ & 4.8 & 1.8 \\
India [9] & 2004 & $9-15$ & 11 & - \\
India [10] & 2004 & $11-17$ & - & 2.4 \\
\hline
\end{tabular}




\section{References}

1. Chan SS, Lam TH, Salili F, Leung GM, Wong DC, Botelho RJ, et al. A randomized controlled trial of an individualized motivational intervention on smoking cessation for parents of sick children: a pilot study. Appl Nurs Res. 2005; 18:178-81.

2. International Obesity taskforce (IOTF). Available from: www.iotf.org/indes. asp.

3. Kuczmarski RJ, Ogden CL, Guo SS, Grummer-Strawn LM, Flegal KM, Mei Z, et al. 2000 CDC growth charts for the United States: methods and development. Vital Health Stat 11. 2002; p. 1-190.

4. Hedley AA, Ogden CL, Johnson CL, Carroll MD, Curtin LR, Flegal KM. Prevalence of overweight and obesity among US children, adolescents, and adults, 1999-2002. JAMA. 2004; 291:2847-50.

5. Ogden CL, Yanovski SZ, Carroll MD, Flegal KM. The epidemiology of obesity. Gastroenterology. 2007; 132:2087-102.

6. Lob-Corzilius T. Overweight and obesity in childhooda special challenge for public health. Int J Hyg Environ Health. 2007; 210:585-9.

7. Ramos E, Barros H. Family and school determinants of overweight in 13-year-old Portuguese adolescents. Acta Paediatr. 2007; 96:281-6.

8. Taheri F, Kazemi T. Prevalence of overweight and obesity in 7 to 18 year-old children in Birjand/Iran. Iran J Pediatr. 2009; 19:135-40.

9. Chhatwal J, Verma M, Riar SK. Obesity among preadolescent and adolescents of a developing country (India). Asia Pac J Clin Nutr. 2004; 13:231-5.

10. Mohan B, Kumar N, Aslam N, Rangbulla A, Kumbkarni S, Sood NK, et al. Prevalence of sustained hypertension and obesity in urban and rural school going children in Ludhiana. Indian Heart J. 2004; 56: 310-4.

11. Health Department. The Ministry of Public Health. Reference values: weight, height of Thai children. 1999.

12. Gibson RS. Principles of Nutritional Assessment. New York:Oxford University Press, 1990. p.187-208.

13. Chadarat M, Tongkumchum P, Tongsinoot S.
Factors affecting high school overweight students in Pattani Province of Thai. Pakistan J Nutrition. 2006; 5: $125-9$

14. Jirapinyo P, Densupsoontorn N, Kongtragoolpitak S, Wong-Arn R, Thamonsiri N. Increasing risks of becoming obese after 6 years in primary school: comparing the relative risks among some schools in Bangkok, Saraburi and Sakolnakorn. J Med Assoc Thai. 2005; 88:829-32.

15. Langendijk G, Wellings S, van Wyk M, Thompson SJ, McComb J, Chusilp K. The prevalence of childhood obesity in primary school children in urban Khon Kaen, Northeast Thailand. Asia Pac J Clin Nutr. 2003; 12: 66-72.

16. Mo-Suwan L, Junjana C, Puetpaiboon A. Increasing obesity in school children in a transitional society and the effect of the weight control program. Southeast Asian J Trop Med Public Health. 1993; 24:590-4.

17. Mo-Suwan L, Tongkumchum P, Puetpaiboon A. Determinants of overweight tracking from childhood to adolescence: a 5 y follow-up study of Hat Yai schoolchildren. Int J Obes Relat Metab Disord. 2000; 24:1642-7.

18. Nguyen T, Kamsrichan W, Chompikul J. Obesity and related factors among students grade 7-12 in Phutthamonthon districts, Nakhon Pathom, Thailand. J Public Health Develop. 2008; 6:91-101.

19. Suttapreyasri D, Suthontan N, Kanpoem J, Krainam J, Boonsuya C. Weight-control training-models for obese pupils in Bangkok. J Med Assoc Thai. 1990; 73: 394-400.

20. Tontisirin K. The changing climate of health and nutrition in Thailand: a report from the institute of nutrition at Mahidol University. Food Nutrition Bulletin. 1999; 20:228-30.

21. Usman Y. Factors related to obesity in primary school children: a case study of Nakhon Pathom Province, Thailand. Mahidol University; 2004. p.31.

22. World Health Organization. Physical status: the use and interpretation of anthropometry. Report of a WHO Expert Committee. WHO:Geneva, 1995. 